


\section{Notas sobre as transparências do filme em Theodor Adorno}

Artigo Inédito

Alessandra Bergamaschi (D) 0000-0002-9534-0643

palavras-chave:

objetos de arte, modernismo, cinema, dialética, mimese, teoria crítica.

keywords: Art Objects, Modernism, Film, Dialectics, Mimesis, Critical

Theory.

palabras clave: objectos de arte, modernismo, cinema, dialética, Mimesis, teoria crítica

*Pontifícia Universidade Católica do Rio de Janeiro (PUC-Rio), Brasil.

DOI: 10.11606/issn.2178-0447. ars.2019.156815

\section{Notes on the Transparencies of Film in Theodor Adorno}

\section{Apuntes acerca de las transparencias del filme en Theodor Adorno}

$\mathrm{O}$ artigo propõe uma panorâmica sobre a dialética entre o mimético e construtivo na constituição da obra de arte, a partir de Teoria Estética, de Theodor Adorno. Essa elaboração servirá para fundamentar a leitura do artigo "Transparencies on Film", no qual o autor discute as especificidades do filme e as possibilidades de resistência à indústria cultural que ele oferece enquanto obra de arte. Um ponto central nesse debate é a alegação de imediatismo e verossimilhança do fotográfico, que, a princípio, impediria as possibilidades construtivas da obra, aspecto fundamental para a arquitetura conceitual da estética de Adorno.

The article proposes an overview of the dialectics between the mimetic and the constructive in Theodor Adorno's Aesthetic Theory. This elaboration will be used to present the article "Transparencies on Film", in which the author discusses the specificities of this medium and the possibilities of resistance that it presents as a work of art in the Cultural Industry. One of the central aspects in this debate is the claim of immediacy and verisimilitude of the photographic, which, at first, would inhibit the constructive possibilities of the work, a fundamental issue for the conceptual architecture of the Adornian Aesthetic.

Proponemos una visada acerca de la dialéctica entre el mimético y el constructivo en la obra de arte a partir de la Teoría Estética, de Theodor Adorno. El análisis servirá para fundamentar la lectura de "Transparencies on Film”, en el cual el autor discute las especificidades del filme y las posibilidades de resistencia que son oferecidas en su calidad de obra de arte. Uno de los puntos centrales del debate es la alegación de inmediatismo y verosimilitud del fotográfico, que impediría las posibilidades constructivas de la obra, aspeto fundamental para la estética de Adorno. 


\section{Sobre o mimético}

$\mathrm{Na}$ seção da Teoria Estética denominada "Mimese e Racionalidade", Theodor Adorno afirma que "a sobrevivência da mimese, a afinidade não conceitual do produto subjetivo com o seu outro, com o não estabelecido, define a arte como uma forma de conhecimento e, sob este aspecto, como também racional"1. Dito em outras palavras:

A plena elaboração subjetiva da arte enquanto linguagem não conceitual é, no estádio da racionalidade, a única figura em que reflete algo parecido com a linguagem da criação, com o paradoxo do efeito de deslocamento próprio dos fenômenos de reflexão. A arte procura imitar uma expressão, que não incluiria intenção humana² .

$\mathrm{O}$ aspecto mimético da arte, que se assemelha à língua ou ao discurso não conceitual, é a essência de sua expressão. E, inegavelmente, diz Adorno, a "expressão", mesmo escapando a definições (ou justamente por escapar delas), é o momento fundamental da arte. A arte é plenamente expressiva quando, através dela, algo de objetivo é subjetivamente mediatizado. Não se trata de simples imitação ou duplicação: "tal é o comportamento mimético da arte: a sua expressão é o contrário da expressão de alguma coisa”’ ${ }^{3}$ A mimese, que, para o artista, liberta o expresso, não pode tornar-se o seu conteúdo psíquico, fazendo da obra sua cópia. Isso porque, como afirmara anteriormente o autor, o momento mimético inalienável na arte é um universal que só pode ser atingido através da idiossincrasia indissolúvel do sujeito individual. E essa idiossincrasia, mesmo caracterizando-o, antecede o sujeito e reverbera através dele ${ }^{4}$.

Miriam Hansen nota que, assim como Benjamin, Adorno identifica uma transformação da percepção sensorial e da subjetividade na modernidade ${ }^{5}$. Mas, enquanto o primeiro enfatiza a natureza coletiva dessa transformação, Adorno insiste na mediação da experiência coletiva a partir das idiossincrasias dos indivíduos, "em cuja arte os impulsos miméticos pré-individuais se refugiam”. Como toda idiossincrasia, ele diz, aquela, em virtude de seu momento mimético pré-individual, "vive de forças coletivas, de que ela própria é inconsciente"7. Esse substrato coletivo encontra sua base material
184

Alessandra Bergamaschi

Notas sobre as transparências

do filme em Theodor Adorno

1. ADORNO, Theodor. Teoria Estética. Lisboa: Edições 70, 1970, p. 68.

2. ADORNO, Theodor. 0 mais como aparência. Ibid., p. 95.

3. ADORNO, Theodor. Expressão como caráter da linguagem. Ibid., p. 132.

4. ADORNO, Theodor. Solipsismo, Tabu mimético, Emancipação. Ibid., p. 56.

5. HANSEN, Miriam. Cinema and Experience. Berkeley: University of California Press, 2012, p. 214

6. ADORNO, Theodor. Subjetividade e coletivo.lbid., pp. 55-56.

7. Ibid. 

O êxito da arte depende então dessa dialética entre coletividade e

8. ADORNO, Theodor. Solipsismo, Tabu mimético, Emancipação. Op. cit., p. 56.

9. Argumento desenvolvido na seção "Finalidade sem fim". Ibid., p. 161

10. BENJAMIN, Walter. Sobre a linguagem em geral e sobre a linguagem do homem.

In: Escritos sobre mito e linguagem. São Paulo: Editora 34, 2011, p. 49-73.

11. JARVIS, Simon. Adorno, a critical introduction Cambridge: Polity Press, 1998, p. 102.

12. ADORNO, Theodor. A espiritualização e o caótico. In: ADORNO, Theodor. Teoria

Estética, Op. cit, p. 112.

13. ADORNO, Theodor. Mimese e Racionalidade. Ibid., p. 69. indivíduo: um contexto de receptividade heterogênea e não idêntica em relação ao inconsciente, ao indeterminado e ao evanescente, para que a arte responda à condição histórica de um mundo industrialmente transformado. O impulso mimético, que coloca uma "resistência determinada à realidade por meio da adaptação a ela", é tão historicamente produzido quanto os procedimentos estéticos.

O comportamento mimético da arte é tal que a sua expressão é "o contrário da expressão de alguma coisa", mas isso não exclui a necessidade de uma articulação sintática ${ }^{8}$. Nisso reside o caráter linguístico que Adorno atribui à arte ${ }^{9}$. Sua (in)comunicabilidade, porém, não se dá a partir da linguagem como meio arbitrário e convencional. Miriam Hansen sugere uma relação entre a concepção de Adorno e as primeiras especulações de Benjamin sobre certos tipos de "coisas-linguagem", que teriam sido fundadas pela linguagem das artes plásticas: "línguas sem nome, não acústicas, línguas emitidas da matéria"10. Uma linguagem muda, anterior ao pensamento classificatório que cria nexos estáveis. Uma linguagem, porém, que permite à obra devolver seu olhar através de sua pura presença. Uma linguagem, como nota Simon Jarvis, que, em sua urgência expressiva, recupera o dado mimético extirpado pela racionalidade moderna, que reduziu a linguagem da arte a seu dado cognitivo, à função de identificar - o que cria, de novo, nexos estáveis ${ }^{11}$.

O belo da natureza também fugiria à observação intencional, sendo acessível somente através de uma intuição involuntária. A obra, segundo Adorno, representa um esforço desesperado para dar voz a essa linguagem muda da natureza e tem como efeito a tentativa de fixar um instante evanescente, "convocá-lo a uma duração". Contradição insolúvel que ele identifica, por exemplo, na prosa de Joyce, que tenta colocar "a linguagem discursiva fora de ação, ou, pelo menos, subordiná-la a categorias formais de construção até ao irreconhecível"12. A percepção e a memória involuntárias, como uma espécie de cegueira, são "vestígios arcaicos incompatíveis com a maturação crescente da razão"13. A obra tornaria possível experimentar impulsos arcaicos de forma não regressiva.

Para Adorno, a aporia da beleza natural, "seu brilho ao desaparecer antes que o esforço para transfigurá-la a torne 
compreensível”, é a aporia da estética como um todo ${ }^{14}$. O belo natural, como o belo artístico - enquanto fenômeno -, é uma experiência de imagens. Hansen escreve que não se trata de imagens como cópias, mas como aparições, e que a palavra, que aparece no texto original em inglês, apparition, combina conotações de epifania e iluminação ${ }^{15}$.

A representação da natureza, ao objetivá-la, faz com que ela desapareça: ambas as experiências - da arte e da natureza são mediadas ideologicamente e, enquanto o primado da origem (atribuído ao belo natural) não existe, o belo artístico pode "abrir os olhos”, através da resistência da obra à realidade empírica. Por outro lado, assim como o belo artístico, a expressão da beleza natural envolve a reciprocidade mimética do observador. No entanto, isso não os subordina ao observador: "sem receptividade, não existiria uma tal expressão objetiva, mas ela não se reduz ao sujeito; o belo natural aponta para o primado do objeto na experiência subjetiva" ${ }^{16}$.

O primado do objeto é confirmado no capítulo "Aparência e Expressão", no qual Adorno critica a crise da aparência no modernismo. Enquanto, ao longo do século XIX, a aparência da obra fora alçada à fantasmagoria, apagando qualquer vestígio de sua produção, a modernidade revolta-se, em seguida, desejando livrarse desse caráter considerado "superficial". O autor cita o exemplo dos impressionistas, que opõem fatos psíquicos à pintura como cópia, e encontra evidência para sua argumentação na "mais recente pseudomorfose na ciência, quase sempre pueril e ignorante, (...) sintoma mais visível de tal involução" ${ }^{17}$.

As obras de arte, tentando se livrar de sua propriedade mais superficial, recaem na simples "coisalidade", como se fosse o caso, diz Adorno, de castigar a sua hybris ao querer ser mais do que arte. Essa revolta contra a aparência é uma revolta contra o elemento ilusório, ao passo que o caráter de aparência, imanente a toda obra, nunca poderá se libertar de algum aspecto de imitação do real de ilusão, por latente que seja. Ao desaparecer de seu contexto autônomo, em função da crescente importância dada à técnica e à falsa racionalidade instrumental, a obra abandonaria então a sua aura enquanto reflexo do humano, expressão do que excede a presença literal da imagem através desse olhar que nos fita de volta.

Com a progressiva autonomia da arte, a reflexividade da obra
186

Alessandra Bergamaschi

Notas sobre as transparências do filme em Theodor Adorno

14. ADORNO, Theodor. A articulação do Belo natural e do Belo artístico. Ibid., p. 81-83.

15. HANSEN, Miriam. Op. cit., p. 232.

16. ADORNO, Theodor. Mimese e Racionalidade. Op. cit., p. 69.

17. ADORNO, Theodor. A espiritualização e o caótico. Ibid., p. 119. 
18. A arte, através da historicidade dos materiais estéticos utilizados, entre os quais constam formas, palavras e sons, que carregam uma sedimentação histórica, coloca o artista frente a escolhas que carregam um sentido e que implicam um juízo. Krcma traz como exemplo alguns desenhos de Eva Hesse, de 1965, em que o tipo de linha pode ser considerado um material, pois carrega referências à fluidez, rapidez da linha matissiana. Hesse repropõe esse signo de forma controlada, em resposta à espontaneidade de Matisse.

Cita também o trabalho

mais seco de Mondrian, e sua manipulação precisa de uma gama muito reduzida de materiais estéticos. Pequenas negações e variações adquirem um grande peso na economia de seu trabalho. Cf. KRCMA, Ed. Seminário:

Figuras do Pensamento, Artes Visuais, Teoria e Poesia, PUCRio, Rio de Janeiro, 2016.

19. Em Dialética do Esclarecimento, de 1947, a mimese persiste apenas nas formas reprimidas vem primeiro", ou de que o objeto aparece para revelar uma essência, ou, ainda, na defesa de uma pretensa objetividade que recusa a mediação estética. Em reação a esse processo, Adorno enfatiza a materialidade da obra - o principal veículo de seu aparecer -, que não representa somente um substrato inerte a ser transfigurado pelo trabalho do artista, mas constituiria ela mesma uma condensação de dados inteligíveis. Os materiais, carregados de marcas sensíveis de sua sedimentação histórica, colocam o artista diante de escolhas críticas decisivas $^{18}$.

A obra é então constituída a partir de elementos empíricos impuros, misturas entre dados fenomênicos e culturais, em uma configuração que não se limita nem às intenções subjetivas do autor, nem à interpretação subjetiva do receptor, mas que aponta e tenciona a relação entre o caráter linguístico da arte e sua dimensão coletiva. A objetividade dessa configuração, diz Jarvis, pode ser entendida como "racional” da mesma forma que a organização de um texto filosófico: o significado cognitivo de um texto filosófico não se fecha na soma de suas proposições, nem na maneira como são organizadas. Seu conteúdo não será idêntico às intenções subjetivas de seu autor; até porque, generalizando, em toda expressão subjetiva, a significação supera o alcance do que se quer dizer e o controle de quem fala. No caso específico da arte, que em termos comunicativos seria colocada do outro lado desse espectro, a articulação entre os dados miméticos e cognitivos resulta em uma configuração enigmática, nunca em clareza conceitual ou transparência comunicativa.

Segundo Jarvis, a mais íntima conexão entre a obra e a linguagem, e sua máxima eloquência, advêm justamente do excesso de significação, que decorre, por sua vez, da complexa organização de elementos que produzem significado resistindo à busca por uma interpretação estável, por uma finalidade determinante. Nessa capacidade de resistência do elemento mimético, que representa, em certa medida, aquilo que conduz do pré-individual ao coletivo, Adorno entrevê a última débil esperança de sobrevida de algum movimento não conciliatório de liberdade através da arte ${ }^{19}$. 
Em Teoria Estética, Adorno fornece uma discussão detalhada Notas sobre as transparências do filme em Theodor Adorno sobre a montagem, que afirma ser o contrário da mimese: "Se, após o começo da modernidade, a arte absorveu objetos estranhos à arte que se integram na sua lei formal não inteiramente modificados, a mimese da arte abandona-se, até à montagem, ao seu contrário" ${ }^{20}$. Ele compara a montagem ao método construtivo, que "restringe criticamente a subjetividade estética, da mesma maneira que as correntes construtivistas - mencione-se Mondrian - constituíam originalmente a antítese das tendências expressionistas”21. Em outro momento, cita o exemplo do cubismo, em antítese, de novo, ao impressionismo, que propõe, por sua vez, uma síntese orgânica e carregada de atmosfera, que procura assimilar objetos "primariamente extraídos da esfera da civilização tecnológica ou seus amálgamas com a natureza", dissolvendo-os "em seus menores elementos, para sintetizá-los em um continuum dinâmico" ${ }^{22}$. Em protesto, os artistas de vanguarda inserem em suas obras recortes de jornais e outros fragmentos do cotidiano, "ruínas literais e não fictícias da empiria", que rompem a "aparência da arte", transformando essa ruptura em "efeito estético"23.

Contudo, se, por um lado, a montagem rejeita - e com toda a razão, como ele diz - o orgânico como ilusório (e o autor recupera aqui a intuição hegeliana de que, em uma relação verdadeiramente dialética, o êxito subjetivo da obra de arte deve ser procurado nas partes em que o sujeito desaparece), por outro lado, a obra de arte puramente construtiva torna-se estritamente objetiva (ele cita como exemplo Adolf Loos) e, em virtude da mimese de formas funcionais, resultaria em algo puramente decorativo, ou em mera reificação ${ }^{24}$. Pois seria inconsistente, então, mover-se do materialismo filosófico ao realismo estético.

A obra é uma aparição que se nega ao desvelamento - e isso só se dá mediante a transposição, decomposição e reconstrução, segundo leis imanentes à obra, da realidade. Somente assim a arte confere à realidade empírica o que lhe pertence, em uma "epifania da sua essência oculta e o justo estremecimento perante ela enquanto monstruosidade"25. E, ainda, nessa passagem contundente: "o primado do objeto só se afirma esteticamente no caráter da arte

e pervertidas da "falsa projeção" que alimentam o anti-semitismo, bem como na mímica ou camuflagem não refletida do "fingir-se morto" por autopreservação, um congelamento ou entorpecimento do ser humano em petrificado. Quando essas reações individuais são organizadas e manipuladas como comportamento coletivo, amplificadas pela imitação das pessoas umas às outras, elas se manifestam na horda fascista, na multidão linchadora e na audiência do cinema. Cf. ADORNO, Theodor; HORKHEIMER, Max. Dialética do Esclarecimento. Rio de Janeiro: Jorge Zahar, 1985.

20. ADORNO, Theodor. Caráter Enigmático, Conteúdo de Verdade; Metafísica. In: ADORNO, Theodor. Op. cit, p. 154.

21. ADORNO, Theodor. Caráter Enigmático, Conteúdo de Verdade, Op. cit., p. 154.

22. ADORNO, Theodor. Consonância e Sentido. Ibid., p. 177.

23. ADORNO, Theodor. Consonância e Sentido. In: Ibid., p. 177.

24. ADORNO, Theodor. Tecnologia. Ibid., p. 73.

25. ADORNO, Theodor. Sociedade. Ibid, p. 289. 
26. Ibid.

27. ADORNO, Theodor. 0 Universal e o Particular. Ibid., p. 244.

28. ADORNO, Theodor. 0 Universal e o Particular. Ibid., p. 246. como historiografia inconsciente, anamnese do subterrâneo, do recalcado e do talvez possível"26.

Em Teoria Estética, Adorno aborda a relação entre a "técnica" - interior ao procedimento estético - e a "tecnologia" necessariamente extra-estética - como elementos também historica e dialeticamente mediados. Assim como seria anacrônico o refúgio da arte no lirismo de uma natureza tida como origem e como algo imaculado, pois essa ideia perdeu qualquer conteúdo de verdade, é anacrônica também a afirmação de uma artesania, como metier, e de uma técnica que escapa ao tecnológico, afirmada melancolicamente por Valéry, que "mistura à sua existência algo de idílico numa época em que nenhuma verdade pode já ser inocente" ${ }^{27}$. Esse é o cerne mesmo da posição adorniana: a necessidade, ao se refletir sobre a arte na era da técnica, de adequar essa prática não tanto ao desenvolvimento tecnológico quanto à modificação das experiências do contexto social e histórico em que as obras aparecem.

Arte é mimese do mundo das imagens e ao mesmo tempo identifica-se com a sua Aufklärung [esclarecimento] através de formas de organização. Mas o mundo das imagens, totalmente histórico, escapa à ficção de um mundo que apagaria as relações sob as quais vivem os homens ${ }^{28}$.

Miriam Hansen nota que o termo Tecnhik, na Teoria Estética, designa principalmente o domínio do material, ou a "inervação" e reflexão sobre os procedimentos e as convenções formais com os quais o artista trabalha e contra os quais se rebela, em tensão dialética com o Gehalt expressivo-mimético da obra - que não é exatamente o mesmo que o conteúdo. Ao tratar de uma técnica industrial, Adorno muda o termo para Technologie, acoplado com o adjetivo "artístico", ou "estético". A fluidez entre os dois conceitos de técnica e tecnologia na Teoria Estética é programática:

Adorno insiste na unidade conceitual entre técnica e tecnologia porque o desenvolvimento da técnica estético-interior, enquanto força produtiva, está ligado ao progresso das forças tecnológicas extra-estéticas: as dinâmicas entre essas relações, porém, são historicamente variáveis ${ }^{29}$. 
Adorno cita o exemplo da música eletrônica, a ele contemporânea, que confirmaria o ponto sobre a origem do termo "técnica” na antiguidade grega, em que "a expressão das obras está amalgamada com uma técnica, com a sua ausência, ou com aquilo que ela ainda não conseguiu realizar" ${ }^{30}$.

Adorno observa que o debate a respeito da dimensão técnica na arte aparece relativamente tarde, após a Revolução Francesa, e está associado à insistência no "primado do fazer". A oposição enfática à ilusão da natureza orgânica da arte é afirmada somente a partir do modernismo (no cubismo e no construtivismo), pois, como ele declara neste trecho,

É retrospectivamente que a técnica se deve reconhecer como constituinte da arte, mesmo para o passado, de um modo incomparavelmente muito mais agudo do que o admite a ideologia cultural que, segundo ela afirma, imagina a era técnica da arte como posteridade e declínio do que outrora foi espontaneamente humano ${ }^{31}$.

A importância dada pelos modernistas à técnica artística, no entanto, ameaça a autonomia estética, exacerbando, como já foi notado acerca da montagem, o paradoxo kantiano: a adequação das obras de arte às normas da racionalidade industrial elimina sua diferença em relação à existência empírica, ao mundo das mercadorias. "A obra de arte estritamente técnica fracassa, mas as que renunciam à técnica são inconsequentes", pois "não é como se a racionalidade matasse sempre o inconsciente, a substância, ou alguma outra coisa; só a técnica capacitou a arte para receber o inconsciente" 32 .

Adorno insiste que a arte moderna deve igualar-se ao industrialismo elevado, para se engajar com modos de experiência irreversivelmente alterados e marcados tanto pelas relações sociais de produção quanto pelo avanço das forças produtivas. As imagens pré-industriais agora não fariam mais sentido: "as imagens do período pós-industrial são imagens de coisas mortas"33. No cânone modernista de Adorno, os estragos causados pelo capitalismo industrial nas condições da vida humana ameaçam a própria capacidade de perceber e compreender essas mudanças, tanto nos termos de uma experiência histórica específica quanto
190

Alessandra Bergamaschi

Notas sobre as transparências do filme em Theodor Adorno

30. ADORNO, Theodor. Sobre as categorias do Feio, do Belo e da Técnica. Op. cit, p. 75.

31. ADORNO, Theodor. Sobre as categorias do Feio, do Belo e da Técnica.lbid., p. 75.

32. ADORNO, Theodor. 0 Universal e o Particular. Ibid., p. 245.

33. Ibid., p. 246. 

inevitavelmente implica uma relação com o mecânico: "é moderna a arte que, segundo o seu modo de experiência e enquanto expressão da crise da experiência, absorve o que a industrialização produziu sob as relações de produção dominantes" ${ }^{34}$.

34. ADORNO, Theodor. Situação. Ibid., p. 47.

35. ADORNO, Theodor. Para uma Teoria da Obra de Arte. Ibid., p. 199.

36. "O 'cinema de papai' corresponde, de fato, ao que os consumidores querem, ou, talvez, ao contrário, fornecelhes um cânone inconsciente do que não deviam querer, ou seja, algo diferente do que estão sendo alimentados".

In: ADORNO, Theodor. Transparencies on Film. In: New German Critique, No. 24/25, Special Double Issue on New German Cinema (Autumn, 1981 - Winter, 1982), pp. 199 - 205. Tradução minha.

\section{Possibilidades de leitura do cinematográfico}

A montagem e o imediatismo de derivação fotográfica são os princípios que definem a especificidade do cinematográfico e seu conjunto de imagens inevitavelmente mediado pela tecnologia, excluindo a priori essa forma artística do domínio da arte autônoma, segundo a articulação de Adorno na Teoria Estética. Os obstáculos estão, em primeiro lugar, ligados à relação do cinematográfico com a semelhança (nesse caso, verdadeira emanação do referente), que representa, para Adorno, uma questão quase intransponível, por prejudicar a polaridade estética essencial entre o mimético e o construtivo, "pois seu caráter representacional projeta os dados empíricos da sociedade de forma muito mais direta que a pintura ou a literatura avançada" ${ }^{35}$. Adorno insiste que a obra de arte deveria ser uma imagem sem imagens, imagem que se afasta da representação icônica, ou cópia, de algo. O segundo obstáculo é a dificuldade do artista de dominar uma técnica inscrita no sistema produtivo da indústria cultural, o que autoriza Adorno a associar a priori qualquer filme produzido na sua época a esse contexto, sem distinções em relação ao cinema "autoral".

No artigo "Transparencies on Film", de 1966, escrito em defesa de jovens cineastas alemães criticados no Festival de Oberhausen por representantes do que ele denomina Daddy's cinema, Adorno introduz uma definição muito precisa da especificidade do meio através da comparação com a literatura: enquanto, no romance, os personagens nunca se assemelham a suas contrapartes empíricas, não importa quão minuciosamente sejam descritos - e, aliás, justamente pela riqueza de detalhes, eles se afastariam ainda mais da realidade empírica, tornando-se esteticamente autônomos -, essa distância é abolida no filme ${ }^{36}$. 
Adorno sugere que, uma vez que o filme é realista, e o imediatismo não pode ser evitado, este deverá, ao contrário, ser afirmado, sendo a improvisação e a introdução de um acaso não guiado alternativas possíveis para esse alcançar esse êxito. Dessa maneira, ele afirma um "naturalismo radical". Como tinha anunciado em Mínima Moralia (1951):

Se o cinema, em harmonia com a exigência de Zola, se rendesse cegamente à representação da vida quotidiana, algo inteiramente exequível com os meios da fotografia em movimento e do registo sonoro, o produto seria um quadro estranho ao que o público está habituado a ver, um quadro difuso e sem ligação com o que lhe é exterior ${ }^{37}$.

Assim, ele continua, o filme adquiriria sua forma apenas a partir de sua pura construção imanente. Isso seria desejável por duas razões. Primeiramente, por eludir as implicações ideológicas da tecnologia no momento da criação da obra:

Enquanto na arte autônoma nada que esteja abaixo do padrão técnico já estabelecido não conta, em relação à indústria cultural - cujos padrões excluem tudo o que não for pré-digerido ou já integrado - as obras que não dominaram completamente sua técnica, resultando em algo consoladoramente descontrolado e acidental, têm uma qualidade libertadora ${ }^{38}$.

Essa defesa dirige-se aos jovens diretores do Festival de Oberhausen, cujos nomes não são citados no artigo. Uma segunda razão, que toca no cerne do cinematográfico, é a de que, de novo nas palavras de Adorno: "independentemente das origens tecnológicas do cinema, a estética do filme deveria basear-se no modo subjetivo de experiência ao qual o filme se assemelha, e que constitui a especificidade de seu caráter artístico" ${ }^{39}$. Cita como exemplo A Noite, filme de 1966 de Michelangelo Antonioni, em que a teoria mais plausível acerca da técnica cinematográfica - que deveria se concentrar no movimento dos objetos -, segundo ele, seria provocativamente negada, ainda que se preserve de forma negativa: "o que não é cinematográfico nesse filme lhe dá o poder de expressar, como através de olhos ocos, o vazio do tempo" ${ }^{40}$.
37. ADORNO, Theodor. Intenção e cópia. In: Mínima moralia. Lisboa: Edições 70, 1951, p. 133.

38. ADORNO, Theodor. Transparencies on Film, p.199. Tradução minha.

39. "Irrespective of the technological origins of the cinema, the aesthetics of film will do better to base itself on a subjective mode of experience which film resembles and which constitutes its artistic character". In: ADORNO, Theodor. Transparencies on Film, p. 201. Tradução minha.

40. ADORNO, Theodor. Ibid., p. 199. 

outro aspecto fundamental do cinematográfico: o fato de lidar necessariamente com uma experiência temporal - nesse caso, pura duração: um naturalismo do tempo, não afetado pelas mediações domesticadas (reacionárias) do cinema pseudorrealista da indústria cultural. As técnicas específicas utilizadas para neutralizar a linearidade temporal do meio, isto é, alguns artifícios da montagem, como as superposições e os flashbacks, tornam-se estratégias convencionais para informar o espectador antes de "necessidades de obras individuais" e devem ser evitados, ou usados com "tato" ${ }^{41}$. Essas formas tecnológicas isoladas, o autor acrescenta, podem desrespeitar a natureza do cinema como linguagem, contradizendo sua lógica interna. O antiformalismo celebrado pelo Jugendstil, e em todos aqueles filmes que tentam "deixar que nuvens e lagoas obscuras falem para eles", de outra maneira, ao escolherem objetos presumivelmente "limpos" de significado subjetivo em busca de autonomia, obtém o resultado oposto.

Seria então possível, pergunta Adorno, libertar a obra cinematográfica da fácil reificação que a reduz a mercadoria, à qual é fadada por seu caráter indicial de cópia, ou reprodução não mediatizada? $\mathrm{O}$ caminho sugerido por ele nesse ensaio, certamente menos lapidar que a Teoria Estética, seria, como já foi exposto, levar às últimas consequências a especificidade do meio, ou seja,

42. Em Teoria Estética, no qual não há brechas para indulgências, Adorno introduz um comentário específico sobre a montagem no cinema, afirmando que a relação entre montagem e fotografia tem, no cinema, seu lugar adequado, e que, apesar da sua dependência redutora da realidade empírica, não se trata de um truque para integrar, na arte, a fotografia e seus derivados. 0 cinema ultrapassaria por imanência a fotografia, "sem a infiltrar de magia fácil". Cita também a tentativa de Benjamin de utilizar a montagem, "que teve o seu acme sob o surrealismo e foi rapidamente suavizada no filme", como único seu imediatismo ${ }^{42}$. No polo oposto, é possível tensionar outra especificidade, o "modo subjetivo de experiência" ao qual o filme se assemelha, que Hansen sugere como sendo, nesse contexto, o "movimento descontínuo das imagens de um monólogo interior" ${ }^{43}$, algo próximo da maneira como a mente humana organiza o fluxo de imagens internas, que transforma a experiência em experiência de imagens. Ou seja, duas estratégias que tendem, de novo, a uma relação dialética.

Quanto aos procedimentos, outro ponto bastante emblemático do texto ressalta que a "resposta óbvia hoje, como quarenta anos atrás, é a da montagem, que não interfere com as coisas, mas as organiza em uma constelação semelhante à da escrita" ${ }^{44}$. Adorno reforça essa intuição em outra passagem potente e evocativa, e inusitadamente metafórica: 
Uma pessoa que, após um ano na cidade, passa algumas semanas nas montanhas abstendo-se de todo o trabalho, pode inesperadamente experimentar imagens coloridas das paisagens consoladoras que chegam a ele ou ela através dos sonhos ou de sonhos de olhos abertos. Essas imagens não se fundem umas às outras em um fluxo contínuo, mas chocam-se uma contra a outra no curso de seu aparecer, assim como as lâminas das lanternas mágicas de nossa infância. É na descontinuidade do seu movimento que as imagens do monólogo interior se assemelham ao fenômeno da escrita: esta última, de forma semelhante, move-se diante de nossos olhos, enquanto fixada em seus sinais discretos ${ }^{45}$.

O modo de experiência expresso no movimento das imagens cinematográficas é análogo aos deslocamentos involuntários da memória, ou seja, imagens mentais (não concretas) que trazem, em sua espessura, a potência da sensação e do afeto. Essas imagens derivam dialeticamente, mas de forma mediada, de sua relação com uma exterioridade: seja ela um sujeito ou a realidade, ou a mistura não homogênea de dados pré-subjetivos e empíricos.

Tal movimento de imagens interiores pode ser, para o filme, o que o mundo visível é para a pintura, ou o mundo acústico, para a música. Como diversão objetivante desse tipo de experiência, o cinema pode tornar-se arte. O meio tecnológico por excelência está, assim, intimamente relacionado à beleza da natureza ${ }^{46}$.

Como "diversão objetivante desse tipo de experiência", ou seja, utilizando como matéria o próprio sistema perceptivo humano, cerne da confluência entre o sensorial e o cognitivo, o mimético e o construtivo, o cinema pode tornar-se arte. Produzindo imaginário, a técnica cinematográfica torna-se mediadora entre um fenômeno físico e outro de ordem psíquica.

Ao evocar o belo natural, Adorno confirma sua crítica à dicotomia entre natureza incontaminada e não mediada versus tecnologia, implicada em Rousseau, e aponta para um resgate do mimético e da natureza através dos meios de produção transformados. A imagem em movimento, através do naturalismo radical e encarnando as possibilidades do sistema perceptivo do

\section{Alessandra Bergamaschi}

Notas sobre as transparências do filme em Theodor Adorno

momento que pode ir além do racionalismo da máquina fotográfica. Cf. ADORNO, Theodor. Crise do sentido. In: ADORNO, Theodor. Teoria Estética, p. 72.

43. HANSEN, Miriam. Op. cit., p. 229.

44. ADORNO, Theodor. Mínima moralia, p. 203.

45. "A person who, after a year in the city, spends a few weeks in the mountains abstaining from all work, may unexpectedly experience colorful images of landscapes consolingly coming over him or her in dreams or daydreams. These images do not merge into one another in a continuous flow, but are rather set off against each other in the course of their appearance, much like the magic lantern slides of our childhood. It is in the discontinuity of their movement that the images of the interior monologue resemble the phenom- enon of writing: the latter similarly moving before our eyes while fixed in its discrete signs". In: ADORNO, Theodor. Transparencies on Film, p. 201. Tradução minha.

46. "Such movement of interior images may be to film what the visible world is to painting or the acoustic world to music. As the objectifying recreation of this type of experience, film may 
become art. The technological medium par excellence is thus intimately related to the beauty of nature." Ibid. Tradução minha.
A constelação estética de Adorno (a expressão e a linguagem enigmática da obra, o belo natural e o belo artístico, a experiência e a mimese, o individual e o coletivo) torna-se válida para analisar as especificidades de um meio fundado na heteronomia, a partir da sua constituição dialética entre presença e ausência, entre o humano e o maquínico. Uma tensão que não varia de forma linear, necessariamente em favor de uma hipertrofia da máquina, mas a partir de modulações que abrem espaço para equilíbrios sutis, que introduzem o não idêntico nas formas históricas do nosso tempo.

\section{Bibliografia}

ADORNO, Theodor. Mínima Moralia. Lisboa: Edições 70, 1951.

ADORNO, Theodor. Teoria Estética. Lisboa: Edições 70, 1970.

ADORNO, Theodor. Transparencies on Film. New German Critique, No. 24/25, Special Double Issue on New German Cinema (Autumn, 1981 - Winter, 1982).

ADORNO, Theodor; HORKHEIMER, Max. Dialética do Esclarecimento. Rio de Janeiro: Jorge Zahar, 1985.

BENJAMIN, Walter. Escritos sobre mito e linguagem. São Paulo: Editora 34, 2012. 
HANSEN, Miriam. Cinema and Experience. Berkeley: University of California Press, 2011.

JARVIS, Simon. Adorno, a critical introduction. Cambridge: Polity Press, 1998.

KRCMA, Ed. Seminário: Figuras do Pensamento, Artes Visuais, Teoria e Poesia, PUC-Rio, Rio de Janeiro, 2016.

Alessandra Bergamaschi é artista visual e pesquisadora ítalobrasileira. É formada em Comunicação pela Universidade de Bolonha e inscrita no programa de Doutorado em História Social da Cultura - linha História da Arte e da Arquitetura na Pontifícia Universidade Católica do Rio de Janeiro (PUC-Rio), com pesquisa sobre as virtualidades introduzidas pelas mediações da imagem técnica na pintura modernista norte-americana. Seus trabalhos já foram expostos em mostras individuais no Centro Cultural Hélio Oiticica (RJ), no Skanes Konstforening (Malmo, Suécia), em mostras coletivas, programas de vídeo e festivais como Doclisboa (Portugal), Festival Internacional de Documentários É tudo verdade (RJ/SP), Semana dos Realizadores, Bienal d'Arts Multimédia Urbains (CICV Belfort, França), Cine Iberê (Fundação Iberê Camargo, Porto Alegre). Em 2015, concebeu, junto a Vanina Saracino, a plataforma OLHO, que conta curadorias de vídeo em Palazzo Grassi (Veneza), Palais de Tokyo (Paris), Cinemateca Brasileira (SP) e Cinemateca do Mam (RJ). Realiza, junto a Sara Manente, o projeto Democratic Forest para a plataforma interdisciplinar de pesquisa a.pass, Bruxelas. 